\title{
Watch out, Someone is Watching You!
}

\author{
Yatin Mehta \\ Indian Journal of Critical Care Medicine (2019): 10.5005/jp-journals-10071-23160
}

The incidence of healthcare-associated infections (HAl) is much higher in the developing countries particularly in India. In one study of International Nosocomial Infections Consortium (INICC), ${ }^{1}$ we found the incidence of central line associated bloodstream infections (CLABSI) to be 5.1/1000 central line days. Ventilator associated pneumonia (VAP) 9.4/1000 mechanical ventilator days and catheter-associated urinary tract infection (CAUTI) 2.1/1000 urinary catheter days, all of which are much higher than the Western incidence. Over and above that we have significant infections with multidrug resistant organisms (MDRO) leading to higher use of expensive antibiotics with increase in length of ICU and hospital stay, mortality and subsequent cost. ${ }^{2}$

Hand hygiene is one of the five key initiatives set out by the World Health Organization (WHO) for patient safety. It recognizes infection control as essential for patient safety and hand hygiene, the most important modality to reduce $\mathrm{HAI}^{3}{ }^{3}$ Education, training, hand hygiene and VAP bundle surveillance (conventional visual means), audit and feedback over a time period have shown a significant reduction of VAP from 17.43/1000 mechanical ventilation days to $10.81 / 1000$, a $38 \%$ VAP rate reduction, ${ }^{4}$ in a large multicenter prospective study.

In this issue of IJCCM, there is a study from Jaipur (Video Surveillance of hand hygiene as a tool for monitoring and impact - not an eye wash) which performed video surveillance (VS) and compared it with direct observation (DO) in ICU, HDU, and ER of a tertiary care hospital over a few months and found a significant difference (which is not a surprise!) between the two and VS showed a much lower compliance rate! This was observed, in our opinion, due to the fact that once people realize that someone is watching you, e.g. infection control personnel who are easily identifiable, they will try to be compliant! This is human nature. That is why there are video security cameras installed everywhere!

The compliance monitored by both techniques improved over a few months. This probably happened as the feedback was given to the departments and culprits and as people realize that someone is watching you (VS) they become law abiding/God fearing!

This is a very simple doable process surveillance method which can easily be replicated. Authors have not done statistical analysis between the groups and different months, which would have added to the scientific value of the paper. In the discussion part, the authors mention that employees privacy was maintained but we do not understand how? In fact, we would suggest that after reviewing the VS the noncompliant staff should be told the same day in order to make them realize their mistakes.

Overall it is a simple study with easy reproducibility and practical beneficial effects to reduce HAI. We as intensivists should put in our best effort to improve hand hygiene compliance and contribute to reduction of HAI's and MDROs in our ICUs. In another small study in this issue, the authors conducted a survey (test)
Medanta Institute of Critical Care and Anesthesiology, Medanta: The Medicity, Gurugram, Haryana, India

Corresponding Author: Yatin Mehta, Medanta Institute of Critical Care and Anesthesiology, Medanta: The Medicity, Gurugram, Haryana, India, Phone: + 911244141414 Extn. 3335; e-mail: yatinmehta @ hotmail.com

How to cite this article: Mehta Y. Watch out, Someone is Watching You! Indian J Crit Care Med 2019;23(5):205.

Source of support: Nil

Conflict of interest: None

on medical students regarding their knowledge of nosocomial infections, hand hygiene, and standard precautions. Seven hundred and twenty-eight MBBS, BDS and BSc students underwent testing pre- and postworkshop on the same. A significant improvement was seen in all parameters posttest. Although it is a very simple study but it does show that education and audit (of knowledge) play important roles in reducing HAl's. Although similar studies have been done in France (developed econonmy) ${ }^{5}$, Ghana ${ }^{6}$ and Ethiopia (underdeveloped) it is good to see its replication in India! Also catch them young! This is the right time (World Hand Hygiene Week) for this issue to come out.

\section{References}

1. Mehta Y, Jaggi N, Rosenthal VD, Kavathekar M, Sakle A, Munshi N, et al. Device-associated infection rates in 40 hospitals from 20 cities of India, data summary for 2004-2013: International Nososcomial Infection Control Consortium's findings. Infect. Control Hsop. Epidemiol 2016; 37(2): 172-181.

2. Mehta A, Rosenthal VD, Mehta Y, Chakravarthy M, Todi SK, Sen N, et al. Device-associated nosocomial infection rates in intensive care units of seven Indian cities Findings of the International Nosocomial Infection Control Consortium (INICC). JHosp Infect 2007; 67: 168-174.

3. World Health Organization. WHO guidelines on hand hygiene in health care. https://www.who.int/gpsc/tools/9789241597906/en/

4. Masroor N, Doll M, Stevens M, Bearman G. Approaches to hand hygiene monitoring: From low to high technology approaches. Int J Infect Dis. 2017; 65:101-104.

5. Tavolacci MP, Ladner J, Bailly L, Merle V, Pitrou I, Czernichow P. Prevention of nosocomial infection and standard precautions: knowledge and source of information among healthcare students. Infect Control Hosp Epidemiol. 2008;29:642-647.

6. Bello Al, Asiedu EN, Adegoke BO, Quartey JN, Appiah-Kubi KO, Owusu-Ansah B. Nosocomial infections: knowledge and source of information among clinical health care students in Ghana. Int J Gen Med. 2011;4:571-574.

7. Tenna A, Stenehjem EA, Margoles L, Kacha E, Blumberg HM, Kempker RR. Infection control knowledge, attitudes, and practices among healthcare workers in Addis Ababa, Ethiopia. Infect Control Hosp Epidemiol. 2013;34:1289-1296.

(c) The Author(s). 2019 Open Access This article is distributed under the terms of the Creative Commons Attribution 4.0 International License (http://creativecommons. org/licenses/by/4.0/), which permits unrestricted use, distribution, and non-commercial reproduction in any medium, provided you give appropriate credit to the original author(s) and the source, provide a link to the Creative Commons license, and indicate if changes were made. The Creative Commons Public Domain Dedication waiver (http://creativecommons.org/publicdomain/zero/1.0/) applies to the data made available in this article, unless otherwise stated. 